\title{
Región de Magallanes \\ Desafíos para la igualdad de género en tiempos de pandemia
}

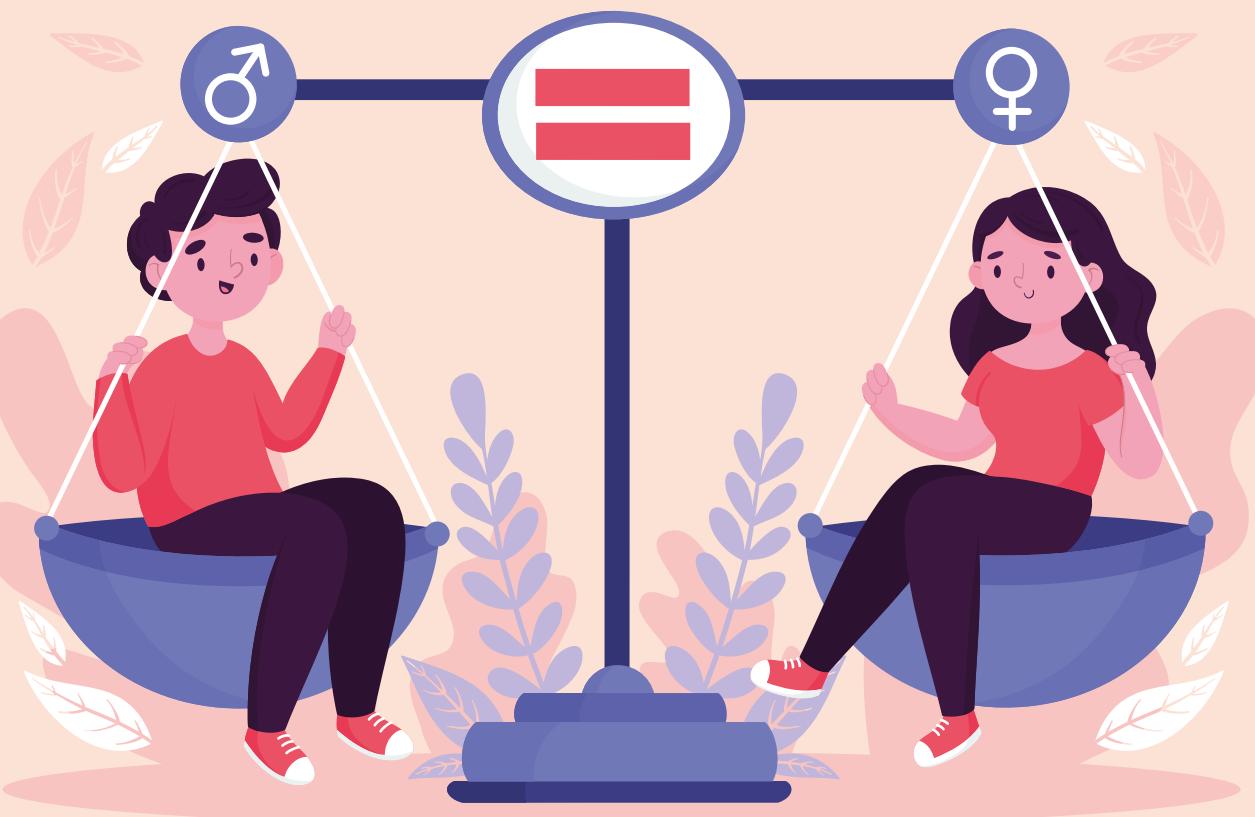

Por Marcela Mandiola, Ph.D. Management Learning and Leadership, Lancaster University, UK. Académica FEN- UAH

A modo de contexto

a posición desmejorada de la mujer en el mundo del trabajo es una realidad reconocida y documentada en nuestro país. Las cifras y los estudios abundan insistiendo en brechas, inequidades y variadas formas de injusticia que dañan la participación de las mujeres en lo laboral y, con ello, el desempeño de las organizaciones y los resultados productivos y económicos en general.

Datos actualizados documentan que las mujeres en Chile seguimos teniendo una menor participación en el mundo del trabajo, $41,2 \%$ versus el $63,1 \%$ de los varones (INE, 2020); la brecha salarial de género es de $-27,2 \%$ en desmedro de las mujeres (INE, 2018), la que se agranda a mayor nivel educacional (GET, 2018).

Más relevante es el contenido del Global Gender Gap Index 2020 del World Economic Forum, en el que Chile aparece en el lugar 111 de un total de 153 países estudiados en sus indicadores de participación económica por género.

Hoy por hoy, si nos posicionamos en la actual situación de pandemia, que en su impacto económico ha sido reconocida como una 'recesión rosa' (Edwards, 2020), el estudio "Teletrabajo, Género y Covid-19 en Cifras" de la Fundación Chile Mujeres (Kreutzberger, 2020), declara que la principal dificultad del teletrabajo ha sido la demanda de las labores domésticas que afecta a un $47 \%$ de las mujeres en esta modalidad y solo a un $28 \%$ de los varones en iguales condiciones. Se agrega a esto que los trabajos con mayor participación femenina son los que tienen menos posibilidades de ser trasladados a modalidad remota, a saber, venta y servicios de comercio, con $65 \%$ de participación femenina; el mismo trabajo doméstico con un $97 \%$ de mujeres a cargo y el área de la salud con un $73 \%$ de participación de mujeres.

Parece ser evidente que los diagnósticos no requieren de mayor abundamiento. Hace rato que la prioridad debiera estar puesta en cómo incidir para la superación de dichas brechas y contribuir a una participación realmente equitativa de la mujer en el mundo del trabajo.

Nuestra Facultad de Economía y Negocios tiene una voz articulada dentro de estos esfuerzos. Entre el 2018 y el 2020, con el financiamiento de la Unión Europea y la colaboración de la Fundación Chile Mujeres, desarrolló el proyecto "Fomento a la Igualdad de Género en el Trabajo". El proyecto ofreció dos versiones del Diplomado de Especialización en Género y Trabajo, en Antofagasta y Concepción, certificando a más de 50 de profesionales de las áreas de Gestión de Personas de distintas entidades pública y privadas. Al mismo tiempo desarrolló seis Manuales de Buenas Prácticas en Género y Trabajo y, muy especialmente, se llevaron a cabo dos Mesas de Diálogo Social, en las ciudades de Concepción y Magallanes, denominadas "Presente y futuro del trabajo: Desafíos para la igualdad de género" en las que participaron líderes y actores relevantes del mundo del trabajo, público y privado, con el objeto de analizar y proponer temáticas que contribuyan a crear y/o fortalecer políticas públicas en dichas materias.

\section{La Región de Magallanes}

Los esfuerzos iniciados con la primera mesa de diálogo en la región austral en 2018 , se continuaron el año recién pasado con una nueva iniciativa de nuestra Facultad, esta vez en colaboración y financiada por la Subsecretaría de Trabajo a través del Programa Diálogo Social. La nueva alianza dio lugar a la Mesa de Diálogo Social "Presente y Futuro delTrabajo: desafíos para la igualdad de género en tiempos de pandemia", Región de Magallanes.

Esta propuesta para la Mesa de Diálogo constataba que a meses de iniciada la crisis sanitaria por Covid 19, el desempleo se posiciona como una de las principales consecuencias en materia económica y social en nuestro país. A nivel regional, la tasa de desempleo en Magallanes alcanzó el 7\% para el trimestre enero-marzo (según cifras aportadas por INE) que, de acuerdo con la tendencia nacional, sigue siendo la tasa más alta de desempleo de los últimos años. 
Durante el desarrollo de la iniciativa de diálogo social, el Observatorio Laboral de Magallanes' compartió estadísticas que indicaban que la brecha salarial en la región era de $-22,4 \%$ en desmedro de las mujeres según datos de la CASEN de 2015. Por otro lado, la población de mujeres inactivas en la región supera en un $50 \%$ a la de los varones según datos del INE al 2017. Sin embargo, lo más relevante es la 'explicación' para dicha inactividad laboral: para casi el $40 \%$ de las mujeres sin ocupación laboral son las responsabilidades familiares permanentes las que les impiden dicho acceso. La misma razón solo explica el 1,9\% de la desocupación laboral masculina. La otra cara de la moneda nos muestra que el $63,6 \%$ de los varones que no se encuentran trabajando en la Región de Magallanes es debido a que estudian; esa misma razón da cuenta de solo el 35,5\% de la mujeres desocupadas. La presentación de Leandra Macías, Directora del Observatorio Laboral local, finaliza enfatizando que las mujeres de la región presentan 'una clara situación de desventaja social' a razón de la 'división sexual del trabajo'.

\section{Se abren nuevas preguntas}

Los números dibujan una realidad, son una manera de mostrar frecuencias, contar, saber cuántos de entre un total; el impacto de una proporción. Esa 'proporción desproporcionada' es la que nos incomoda, la brecha entre las dos cantidades es lo que nos compele a enfrentarla y, en el mejor de los casos, hacerla desaparecer. Hemos constatado claramente que hay menos mujeres en el mundo laboral en general y que esas menos mujeres están además en posiciones muy desmejoradas respecto de los varones. El desafío, entonces, es desplegar estrategias y proponer soluciones. Sin 'responsabilidades' mucho más arraigadas en la poderosa socialización de lo femenino.

Leandra Macias en su intervención en la Mesa de Diálogo Social lo expone con claridad, mucho del problema tiene que ver con que históricamente la demanda social para las mujeres no ha sido la de trabajar remuneradamente fuera del hogar. Volcarse a lo público laboralmente ya es parte de los espacios que las mismas mujeres han logrado conquistar para sí mismas, pero las tradicionales labores de cuidado permanecen aún, casi inamovibles, en sus manos.

\section{Mesa de diálogo social}

El diálogo social, entendido como una dinámica de negociaciones y consultas entre representantes de los gobiernos, los empleadores y los trabajadores impulsada por la OIT, busca establecer consensos e implicar democráticamente a dichos agentes en el abordaje de soluciones a sus desafíos económico-sociales.

En este caso, la convocatoria en Magallanes se concentró en los desafíos para la igualdad de género en tiempos de pandemia. En los confines del sur, el norte fue discutir respecto de estrategias que fomenten la incorporación de las mujeres al ámbito de la mineria local en particular. A través de una serie de sesiones de trabajo tripartito, se abocaron a la tarea representantes del gobierno regional en lo técnico y de los empleadores junto con la participación de los colectivos sindicales del gremio.

En la línea de lo que mencioné más arriba, las reuniones tripartitas se concentraron en la elaboración de un diagnóstico respecto del empleo femenino en la región y sus particulares requerimientos. Aparece entonces como prioritaria "la

\section{"Para casi el $\mathbf{4 0 \%}$ de las mujeres sin ocupación laboral en Magallanes, son las responsabilidades familiares permanentes las que les impiden dicho acceso. La misma razón solo explica el 1,9\% de la desocupación laboral masculinas"}

embargo, en este momento lo que es realmente importante es levantar nuevas preguntas respecto de una realidad social, que de tan evidente (y evidenciada), tiende a normalizarse.

Puede sostenerse que mucho de lo que se ofrece como soluciones intensifican la 'oferta' de trabajo, en otras palabras, se busca atraer a las mujeres al trabajo desde el trabajo. Si bien hay en ello un aporte relevante, su foco, más bien estrecho, no alcanza a considerar que el acceso al trabajo es una demanda (im)posible cuando compite con organización de los tiempos de trabajo y descansos de sus trabajadores y trabajadoras... en pos de la corresponsabilidad parental en el mundo del trabajo remunerado"(FEN UAH, 2020 anexo 15). Se identifica y reconoce entonces la importancia, y también la imbricación del mundo del trabajo y las necesidades de cuidado de la población. Las propuestas construidas se orientan a la conciliación entre ambos mundos con el concurso de las partes involucradas. No obstante, la elaboración de los hallazgos durante el trabajo de diálogo so- cial permitió a este grupo de agentes relevar que la segregación ocupacional opera como un factor estructural en la menor participación laboral de las mujeres. Lo anterior tiene directa relación con la crisis de los cuidados en la sociedad actual (Carrasco, 2016), abordarla fue identificado como necesario para poder incidir en la participación laboral de las mujeres.

Las conclusiones del proceso de dialogo social, en este caso, destacan que "las brechas de género no se acaban con la incorporación de las mujeres al mercado laboral. Sino que debe existir acciones por parte de las organizaciones que promuevan y aseguren su permanencia" (FEN UAH, 2020 anexo 15).

Desde la división sexual a la división generizada del trabajo: cuestionando supuestos

Preguntarnos por la división sexual del trabajo invita a considerar de manera más amplia las ideas que las sociedades normalmente tienen acerca de cuál tipo de educación, ocupaciones y posiciones profesionales corresponden a un género en particular.

Hablamos aquí del simbolismo de género, lógica discursiva más profunda que la división de sexos, no sólo significa que un trabajo particular es apropiado para hombres y/o mujeres, si no que se refiere también a significados no explícitos y fantasías inconscientes asociadas a dicha división.

Mientras que la división sexual apunta simplemente a explicitar que hay trabajos más apropiados (sólo) para mujeres y (sólo) para hombres, el simbolismo de género refiere a la lógica cultural detrás de esos tipos.

Las nuevas preguntas que venimos a proponer en esta reflexión problematizan la construcción cotidiana de símbolos e imágenes que explican, expresan y refuerzan dichas diferencias generizadas.

Hablamos de prácticas generizantes que se expresan en el lenguaje, la ideología y la cultura popular, entre otros, y que todos y todas estamos comprometidos a revisar y desafiar.

La construcción de divisiones a lo largo de líneas del género, tal como explicitó Joan Acker en 1992, involucra la constitución de divisiones del trabajo a través de conductas permitidas y no permitidas para cada uno de los géneros, la distribución del espacio físico, más importante aún, la distribución del poder en el ámbito de lo laboral. Se hace imprescindible entonces echar luz sobre aquellos significados institucionales que construyen $y$, sobre todo, mantienen dichas divisiones inamovibles en su lugar y que hacen que a pesar de los esfuerzos descritos en estas líneas la inequidad laboral de la mujer siga siendo una prioridad cuando hablamos de justicia, democracia y derechos humanos. $\mathbf{E}$

(1) Presentación de Leandra Macias Directora Observatorio Laboral Magallanes, seminario de cierre el 10 de diciembre de 2020.

\section{Bibliografía}

Acker, J. (1992). From Sex Roles to Gendered Institutions. Contemporary Sociology, 21(5), 565-569.

Carrasco, C. (2016) Sostenibilidad de la vida y ceguera patriarcal. Una reflexión necesaria. ATLÁNTICAS - Revista Internacional de Estudios Feministas, 2016, 1, 1, 34-57

ComunidadMujer (2018). Informe GET 2018: Género, Educación y Trabajo. Avances, contrastes y retos de tres generaciones. Chile

Edwards, S. (2020) Esta horrible recesión rosa, mujeres y la doble carga del Covid-19. Columna La Tercera, 12 septiembre 2020.

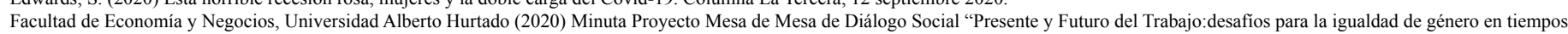
de pandemia", Región de Magallanes.

INE (2020) Encuesta Nacional de Empleo Trimestre Abril - Junio. www.ine.cl

Kreutzberger, S. (2020) Teletrabajo, Género y Covid-19 en cifras. Fundación Chile Mujeres. www.chilemujeres.cl 